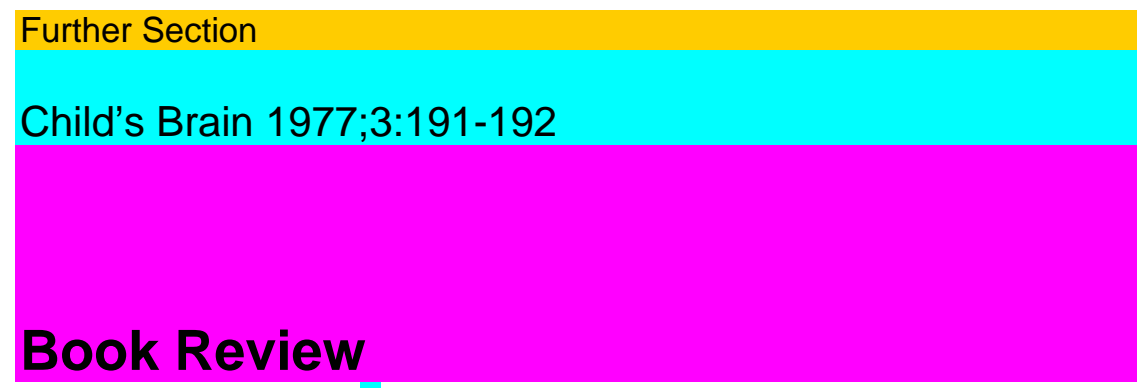

Studies in Hydrocephalus and Spina bifida. Supplementum 35 to Developmental Medicine and Child Neurology. Heinemann, London 1975. $160 \mathrm{pp}$.

This supplement is a compilation of presentations at the annual meeting of the Society for Research into Hydrocephalus and Spina bifida held in Glasgow, June 25-29, 1975. The supplement contains contributions from medical, engineering and sociological fields involved in the study of hydrocephalus and spina. $5 / 8$ ifida. The scope of this meeting is broad but aimed specifically at presenting new a:iud relevant studies into these diseases. The majority of papers presented at this meeting are excellent.

The first three papers are concerned with embryogenesis, physical bïochemical characteristics and cell population studies in human and animal dysia, pliic disease. These are good examples of basic science investigations and again point out the broad scope of this meeting. Williams' paper entitled 'Cerebrospinal Fluid Pressure Gradients in Spina bifida cystica, with Special Reference to the Arntold-Chiari Malformation and Aqueductal Stenosis' suggests that all the intracran $;$ aL manifestations of spina bifida cystica may be due to low intraspinal pressure, 'wlich results from initial failure of the neural tube to close during embryogenesis. It is evident, from this paper, that the controversy continues as to the etiology and relation of spina bifida and the Arnold-Chiari malformation.

Epstein, Hochwald, Wald, and Ransohoff's paper on 'Avoidance of Shunt Dependency in Hydrocephalus' is an excellent example of the application of laboratory science to clinical management of a disease. Several papers were presented by the New York University groups and as always they were imaginative.

Engineering problems in shunt design were discussed by Dawson, Derwin, and Hefwood and pointed out a common problem, the need for communication between illc neurosur-geon and the designer. 'Antibiotic Prophylaxis in Shunt Surgery' by Bays ton, which showed no beneficial effect of prophylaxis, joins the seemingly endless series of papers which deal with this yet unresolved problem of prophylaxis in surgery.

No meeting dealing with these diseases would be complete without japers concerning selection. The search for criteria to exclude patients from treatment continues. Lonton, Barrington and Lorber demonstrate that lacunar skull deformities, previously suggested as indicative of later lowered intelligence, exist in 9VJo of these children and therefore is not a useful criteria for selection. Laurence and Beres-ford's paper, 'Continence, Friends, Marriage and Children in 51 Adults with Spina bifida', found that this group of 51 patients were amazingly cheerful and have done 
reasonably well. However, they hastened to point out that these were survivors prior to 1960 and most had escaped without hydrocephalus, and none had significant mental handicaps. Some doubt exists as to whether children surviving now will faire as well. Aggressive treatment has resulted in survival of more serious; ly disabled patients. 
192 


\section{Book Review/Varia}

In summary, this supplement, drawn from the annual meeting of the Society for Research into Hydrocephalus and Spina bifida, as always, attracts papers from various experts dealing with these diseases. The state of the art is presented in both factual and controversial form. This supplement is essential reading for any individual involved in the care of patients with hydrocephalus and/or myelomeningocele.

David G. McLone, Chicago

Varia

Society for Research into Hydrocephalus and Spina Bifida Annual Scientific Meeting, University of Sheffield, Sheffield 29th June to 2nd July 1977

Further details can be obtained from the Honorary Secretary: Mr. Geoffrey Walker, Queen Mary's Hospital for Children, Carshalton, Surrey (England) 